\title{
Análise microbiológica da água bebida pela comunidade duas cachoeiras, Povoado Vila Real, Barra do Corda-Maranhão
}

Este trabalho analisou a presença de coliformes totais e termotolerantes na água para hidratação da comunidade Duas Cachoeiras, do Assentamento PA Cachimbeiro da Vila Real, Barra do Corda - MA. Refere-se a uma pesquisa com abordagem quantitativa, onde foram coletadas amostra de água usada para beber em 14 casas da comunidade que conta com 20 famílias. A metodologia para as análises da água foi executada conforme a determinação do Número Mais Provável (NMP) de coliformes na água pela análise microbiológica de acordo o Procedimento de Análise - M048 A, Kit Microbiológico Colipaper, além de teste de pH por meio de fitas indicadoras descartáveis, marca Macherey-Nagel, Ref. 92110. Os resultados foram analisados à luz da Portaria de Consolidação $\mathrm{N}^{\circ} 5$, de 28 de setembro de 2017, do Ministério da Saúde. De todas as amostras de água analisadas, apenas a da casa representada na pesquisa pelo número 7 , apresentou-se apta para o consumo humano, ou seja, isenta de coliformes, o que está associado ao fato da moradora não consumir água do rio que margeia a comunidade e semanalmente comprar água mineral na sede da cidade de Barra do Corda/MA. Assim, os resultados demonstraram que a água bebida por grande parte da comunidade, que é proveniente do Rio Corda, sem passar por nenhuma forma de tratamento, encontra-se fora dos padrões de potabilidade para consumo, o que alerta para a necessidade de uma vigilância contínua de sua qualidade, o provimento de uma fonte adequada de água para abastecimento do assentamento, além de acompanhamento do sistema de saúde devido a ocorrência de possíveis doenças diarreicas.

Palavras-chave: Análise microbiológica; Assentamento; Potabilidade.

\section{Microbiological analysis of drinking water by the two waterfalls community, Povoado Vila Real, Barra do Corda-Maranhão}

\begin{abstract}
This work analyzed the presence of total and thermotolerant coliforms in the water for hydration of the Duas Cachoeiras community, from the PA Cachimbeiro settlement in Vila Real, Barra do Corda - MA. It refers to a research with a quantitative approach, where a sample of water used for drinking was collected in 14 houses in the community, which has 20 families. The methodology for the water analysis was performed according to the determination of the Number of Most Probable (NMP) of coliforms in the water by microbiological analysis according to the Analysis Procedure - M048 A, Colipaper Microbiological Kit, in addition to $\mathrm{pH}$ test through indicator strips disposable, brand Macherey-Nagel, Ref. 92110. The results were analyzed under the light of Consolidation Ordinance No. 5, from September 28, 2017, of the Ministry of Health. Of all the water samples analyzed only one from the house represented in the survey by number 7 , was able to human consumption, that is, free from coliforms, which is associated with the fact that the resident does not consume water from the river that borders the community and weekly buys mineral water in the city of Barra do Corda-MA. There fore, the results showed that the water drunk by a large part of the community, which comes from the Rio Corda, without any form of treatment, is outside the standards of drinking for consumption, which warns of the need for continuous surveillance of its quality, the provision of an adequate source of water to supply the settlement, in addition to monitoring the health system due to the occurrence of possible diarrheal diseases.
\end{abstract}

Keywords: Microbiological analysis; Settlement; Potability.

Topic: Uso de Recursos Naturais

Reviewed anonymously in the process of blind peer.
Received: 10/05/2020

Approved: 07/06/2020
Nilson dos Santos Loiola ii

Instituto Federal do Maranhão, Brasil

http://lattes.cnpq.br/4277571699501201

http://orcid.org/0000-0002-4641-5864

nilson.loiola@ifma.edu.br

Mayara Letícia Costa Sobrinho (iD)

Unidade de Ensino Superior do Centro Maranhense, Brasil

http://lattes.cnpq.br/3846985225389909

http://orcid.org/0000-0003-2801-9152

mayara.costa@unicentroma.edu.br
Referencing this:

LOIOLA, N. S.; COSTA SOBRINHO, M. L.. Análise microbiológica da água bebida pela comunidade duas cachoeiras, Povoado Vila Real, Barra do Corda-Maranhão. Revista Ibero-Americana de Ciências Ambientais, v.11, n.4, p.441-449, 2020. DOI: http://doi.org/10.6008/CBPC2179$\underline{6858.2020 .004 .0037}$ 


\section{INTRODUÇÃO}

Por muitos anos o senso comum tratou a água como um recurso infinito, de livre exploração, mas atualmente se sabe que é um recurso que requer cautela isso porque a parcela doce consumida pela humanidade está disponível em uma pequena parte do planeta quando em comparação com as porções de terra e de água salgada. Essa pequena parcela de água é muito importante, isso porque é a fonte mais conveniente e barata para as necessidades domésticas, industriais e laborais, os habitats de água doce são gargalos do ciclo hidrológico, além da sua importância para os sistemas de captação e esgoto pela maioria das cidades do mundo (ODUM et al., 2008).

A água é a substância mais essencial para a manutenção da vida, em todos os seus estágios, contribuindo de forma insubstituível e, apesar de sua importância, o abastecimento hídrico das populações tem se tornando um dos grandes problemas de saúde pública do século XXI (PORTO et al., 2011). Em consequência às ações humanas o ecossistema hídrico tem sido afetado constantemente por uma soma de fatores: desenvolvimento populacional, ocupação desordenada do solo e o aumento de residências sem planejamento e estrutura apropriada gerando problemas de ordem sanitária devido à carência de saneamento básico, tornando a água imprópria para o consumo.

Seja na regulação do metabolismo dos organismos ou no desenvolvimento de atividades produtivas e de lazer, a água requer o atendimento a exigências de disponibilidade e o enquadramento nos padrões de qualidade, de modo a garantir a salubridade das suas utilizações, ou seja, a presença ou não de contaminantes toleráveis e os padrões sanitários de qualidade da água são estipulados de acordo o uso pretendido (VIEIRA et al., 2016).

Assim, pode-se afirmar que várias fontes de água doce, por mais que tenham o caráter de balneabilidade, com finalidade de recreação e banho, não quer dizer que atendam a requisitos de potabilidade, não sendo própria para o consumo humano e não podendo ser ingerida antes de passar por algum processo de tratamento.

O recomendado para a água de consumo doméstico, em especial com finalidades de hidratação, é que esta seja isenta de microrganismos, principalmente os termotolerantes. A presença de grupos microbianos na água, como os coliformes (grupo de bactérias naturais de diversos habitats e não patogênicas, bactérias patogênicas do grupo dos coliformes fecais e bactérias que compõem o grupo dos coliformes totais), sugere contaminação por fezes e/ou dejetos contendo carga fecal, representando um risco à saúde pública uma vez que a água passa a assumir o papel de um veículo de transmissão indireta de doenças diarreicas.

Os coliformes totais são um grupo de bactérias capazes de promover a fermentação da lactose com produção de ácidos, aldeídos e gás a $35^{\circ} \mathrm{C}$ entre 24 e 48 horas. Inclui-se no grupo de coliformes totais bactérias como bastonetes Gram-negativos não esporogênicos, anaeróbios facultativos ou aeróbios, compreendendo cerca de 20 espécies e entre elas encontram-se bactérias originárias do trato gastrintestinal de humanos e outros animais homeotérmicos e ainda vários gêneros e espécies de bactérias não entéricas 
(TORTORA et al., 2012; SILVA et al., 2009).

Já os coliformes fecais ou coliformes termotolerantes são um subgrupo de bactérias dentro do grupo dos coliformes totais e que possuem a capacidade de fermentar lactose a $44-45^{\circ} \mathrm{C}( \pm 0,2)$ em 24 horas, com destaque para a Escherichia coli (E. coli), que possui origem exclusivamente fecal (TORTORA et al., 2012; SANTOS et al., 2014).

De acordo com a Portaria de Consolidação N 5, de 28 de setembro de 2017 do Ministério da Saúde e seguindo os critérios estabelecidos para a potabilidade da água para o consumo, deve-se buscar atender aos padrões físico-químicos e microbiológicos fixados em lei e estabelecidos pela portaria supracitada onde diz que a água adequada ao consumo humano deve estar livre de E. Coli e de bactérias do grupo dos coliformes totais em cada $100 \mathrm{ml}$ de amostra testada (BRASIL, 2017).

Assim, grande parte das doenças de veiculação hídrica são provocadas, principalmente por microrganismos patogênicos de origem entérica, animal ou humana, facilmente transmitidos pela rota fecaloral, onde uma vez excretados nas fezes de indivíduos infectados passam a ser ingeridos por outros indivíduos ou o mesmo (se reinfestando) através da água ou alimento contaminado pela água poluída por fezes ou dejetos dessas (GREGHI, 2005).

Nesse sentido, o aumento da incidência de doenças gastrointestinais pode ter relação direta com a água disponível para consumo humano de uma região, o problema em tratar o tema de forma assertiva é o fato de que no Brasil as notificações de casos diarreicos, mediante exames e sua especificação, não é uma ação obrigatória no sistema de saúde, a não ser para os casos de Cólera.

A degradação da qualidade da água e a contaminação dos corpos hídricos são resultados da ação predatória no ambiente, sobretudo aquela proveniente do esgotamento sanitário, o que tem aumentando muito o risco de transmissão de doenças, ainda mais quando esses locais são utilizados pela população através de um contato primário com a água (MARIANO, 2008). Portanto, o presente trabalho buscou realizar uma análise microbiológica da água que está sendo bebida pela comunidade Duas Cachoeiras, do Assentamento PA Cachimbeiro, da Vila Real, área rural do município de Barra do Corda, Maranhão.

Ele foi conduzido com os objetivos de avaliar os parâmetros microbiológicas e valor do $\mathrm{pH}$ de amostras da água reservada pelos moradores com a finalidade de hidratação, isso porque a referida comunidade não é servida de água encanada, não possui poço artesiano e, pelo fato de estarem assentados a cerca de 100 m do Rio Corda, esses recorrem à captação de água direto das margens do rio para beber e prover suas necessidades domésticas.

Avaliar a presença de bactérias do grupo dos coliformes na água bebida pela comunidade Duas Cachoeiras da Vila Real, área rural e ribeirinha de Barra do Corda/MA se faz extremamente importante uma vez que a mesma, além de estar afastada também é carente de programas de saúde que atendam suas necessidades como o acompanhamento e resolução dos casos de doenças diarreicas, além da comunidade não possuir filtros ou mesmo realizarem outros procedimentos para tratamento da água que bebem e que usam para cozer os alimentos. 


\section{METODOLOGIA}

\section{Área de estudo}

O estudo foi realizado na comunidade Duas Cachoeiras, do Assentamento PA Cachimbeiro/Vila Real (Coordenadas Geográficas: S 5044'19,296" e W 4517'51,851"'/GPS GARMIN), localizado à cerca de 100 metros do Rio Corda, no município de Barra do Corda/MA. As coletas foram realizadas no mês de dezembro de 2019 , anterior ao período de intensas chuvas, que segue de janeiro a maio (SOUZA et al., 2015), e as casas foram identificadas por números sequenciais não correspondendo ao número real de registro do lote disponibilizado pelo INCRA.

\section{Análise do pH da Água}

As amostras de água foram submetidas ao teste de pH por meio de fitas indicadoras descartáveis, marca Macherey-Nagel, Ref. 92110.

\section{Análise microbiológica de água para hidratação humana}

Para a determinação do Número Mais Provável (NMP) de coliformes na água foi realizada análise microbiológica de amostras de água de acordo o Procedimento de Análise - M048 A, Kit Microbiológico Colipaper. O kit Microbiológico Colipaper funciona à base de dois meios de cultura cromogênicos desidratados (Salmon-GAL e X-glicuronídeo) que possibilita a deteç̧ão de coliformes totais e fecais (Termotolerantes) em um mesmo teste (VILLELA, 2010), conforme descrito no Quadro 1.

Quadro 1: Teste.

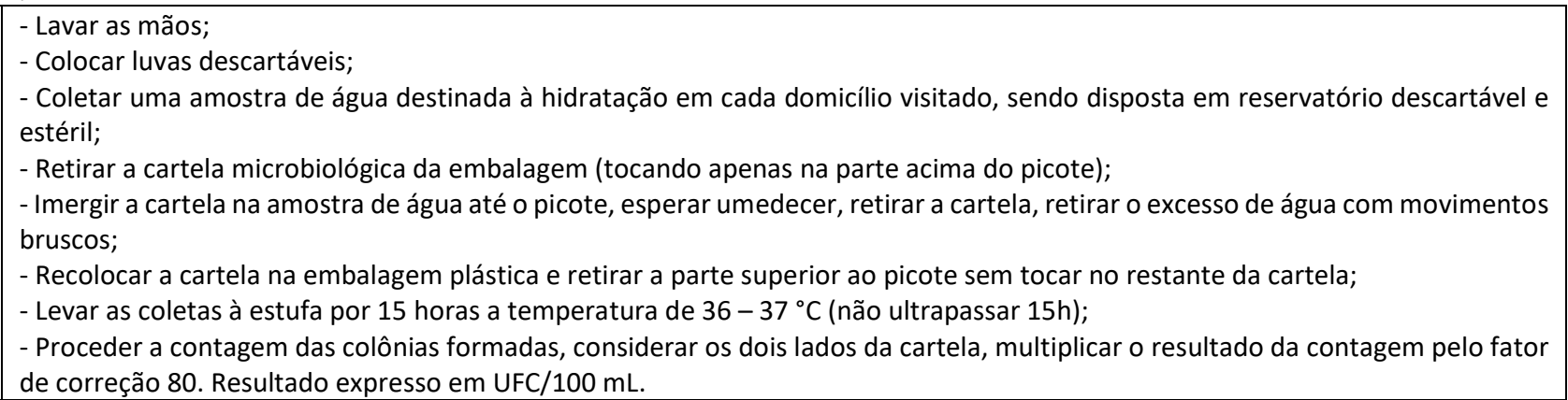

\section{Interpretação das Cartelas Microbiológicas}

As cartelas, após incubação, devem ser observadas (dos dois lados, sem contar pontos em duplicidade, ou seja, o mesmo ponto marcado dos dois lados) à procura de pontos com coloração variando de Violeta à Azul e de Róseo à Vermelho. Tais pontos formados correspondem a colônias bacterianas desenvolvidas. Os pontos com coloração entre tons de Violeta à Azul correspondem a Escherichia coli Coliformes fecais, pontos com coloração variando entre tons de Róseo à Vermelho correspondem a Enterobacter cloacae e a soma de todos os pontos contabilizam os chamados Coliformes Totais.

OBS: Para coletas em campo, acomodar as cartelas em um saco plástico e dispor em caixa térmica com pouco gelo (evitar congelamento). 


\section{Tabulação dos dados}

Os dados foram tabulados com o auxílio de planilhas do Excel, seguidas da plotagem de gráficos no programa BioEstat 5.0 através da aplicação de Correlação Estatística de Pearson, pareando o NMP de cada classe bacteriana identificada nas amostras com o NMP para Coliformes totais dessas mesmas amostras, afim de confirmar qual classe bacteriana, significativamente, contribuiu para o resultado de NMP de Coliformes totais.

\section{RESULTADOS}

A água utilizada para consumo humano deve ser isenta de microrganismos, dentre eles os mais investigados é a presença de bactérias como coliformes fecais e coliformes totais, uma vez que a presença dessas indica presença de carga fecal na água, que passa a ser uma forma indireta de transmissão de doenças diarreicas. Assim, a Tabela 1 mostra os resultados, por casa (numeradas de 1 a 14), para os testes de pH, Coliformes fecais (E. coli) e Coliformes totais (soma das colônias bacterianas proliferadas), com relação ao padrão estabelecido pelo Ministério da Saúde.

Tabela 1: Resultado da análise do NMP de colônias bacterianas por cada $100 \mathrm{~mL}$ de amostra de água

\begin{tabular}{|c|c|c|c|c|c|}
\hline \multirow[b]{2}{*}{ Casa } & \multicolumn{4}{|l|}{ RESULTADOS } & \multirow[b]{2}{*}{$\begin{array}{l}\text { Padrão* } \\
\text { (p/ } 100 \mathrm{~mL} \text { ) }\end{array}$} \\
\hline & $\mathrm{pH}$ & $\begin{array}{l}\text { E. coli } \\
\text { (UFC/100 mL) }\end{array}$ & $\begin{array}{l}\text { E. cloacae } \\
\text { (UFC/100 mL) }\end{array}$ & $\begin{array}{l}\text { Coliforme totais } \\
\text { (UFC/100 mL) }\end{array}$ & \\
\hline 1 & 7 & 480 & 480 & 960 & Ausência \\
\hline 2 & 6 & 80 & 720 & 800 & Ausência \\
\hline 3 & 6 & 160 & 160 & 320 & Ausência \\
\hline 4 & 7 & 0 & 6880 & 6880 & Ausência \\
\hline 5 & 7 & 0 & 320 & 320 & Ausência \\
\hline 6 & 7 & 160 & 560 & 720 & Ausência \\
\hline 7 & 6 & 0 & 0 & 0 & Ausência \\
\hline 8 & 6 & 160 & 4480 & 4640 & Ausência \\
\hline 9 & 7 & 0 & 480 & 480 & Ausência \\
\hline 10 & 7 & 160 & 560 & 720 & Ausência \\
\hline 11 & 6 & 480 & 1920 & 2400 & Ausência \\
\hline 12 & 7 & 160 & 1040 & 1200 & Ausência \\
\hline 13 & 7 & 160 & 1360 & 1520 & Ausência \\
\hline 14 & 7 & 240 & 1760 & 2000 & Ausência \\
\hline$M \pm D P$ & $6,643 \pm 0,479$ & $160 \pm 151,186$ & $1480 \pm 1855,278$ & $1640 \pm 1846,882$ & Ausência \\
\hline
\end{tabular}

*Padrão: De acordo com a Portaria N 5, de 28 de setembro de 2017, do Ministério da Saúde

Legenda: UFC - Unidades Formadoras de Colônias; NMP - Número Mais provável; M - Média; DP - Desvio Padrão

Os resultados mostraram que em apenas uma casa (casa $\mathrm{N}^{\circ} 7$ ) não foram detectadas nenhum grupo bacteriano. A Tabela 1 também mostra que em algumas casas a amostra de água testada não apresentou a presença de coliformes fecais ( $E$. coli), sendo elas as casas 4, 5, 9, além da casa 7 já mencionada anteriormente e isenta de qualquer classe de bactérias analisada.

Também foi possível perceber que o NMP de colônias de bactérias Escherichia coli foi, de forma geral, inferior e até nula, quando comparado ao NMP de colônias de Enterobacter cloacae. Em virtude dessa variação no NMP que a análise de correlação entre os valores para $E$. coli e o NMP de Coliformes totais não demonstrou ter correlação estatística significativa, conforme Figura 1. 


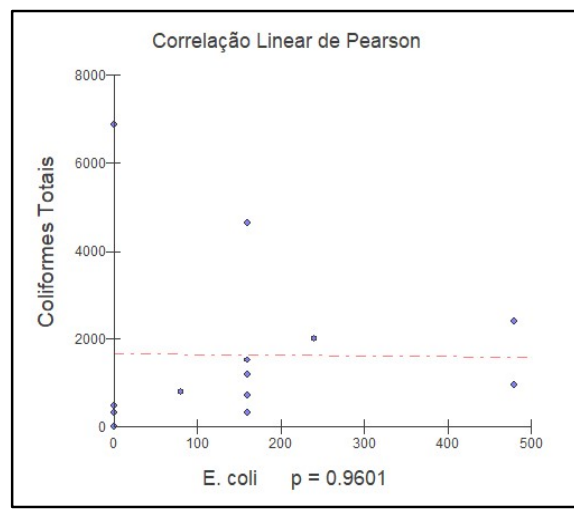

Figura 1: Correlação Linear de Pearson entre Coliformes fecais $\times$ Coliformes Totais (Correlação de Pearson: $r=-$ 0,$\left.0147 ; R^{2}=0,0002 ; p=0,9601 ; N=14\right)$.



Figura 2: Correlação Linear de Pearson entre Enterobacter cloacae $x$ Coliformes Totais (Correlação de Pearson: $\left.r=0,9967 ; R^{2}=0,9934 ; p<0,0001 ; N=14\right)$.

Em contrapartida, o NMP de E. cloacae nas amostras das casas analisadas foi muito elevado e demonstrou ter muita correlação estatística ( $99 \%$ de correlação) com o NMP encontrado para a quantidade de Coliformes totais, conforme Figura 2.

\section{DISCUSSÃO}

Os resultados mostraram que em apenas uma casa (casa $\left.N^{\circ} 7\right)$ não foram detectadas nenhum grupo bacteriano, isso porque a água consumida pela família é mineral, comprada semanalmente na sede do município de Barra do Corda/MA. As demais famílias, por condições financeiras insuficientes e/ou indisponibilidade de se deslocar para a sede do município, ingerem água captada diretamente do Rio Corda, que se localiza à cerca de 100 metros de distância de onde a comunidade está assentada.

Além do fato de consumir água diretamente do rio, as famílias não possuem filtros, purificadores de água ou não realizam nenhum procedimento para minimizar os possíveis efeitos ao organismo humano provenientes de microrganismos patogênicos. Mesmo as casas testadas, identificadas pelos números 4, $5 \mathrm{e}$ 9, não terem indicado a presença de coliformes fecais pela ausência de colônias de Escherichia coli, isso não às exclui do risco haja visto que houve a proliferação de E. cloacae importante na determinação de Coliformes totais, não estando, por tanto, isenta de grupos coliformes, o que as tornam impróprias para beber.

Segundo Barrell et al. (2002), a ausência de E. coli nos estudos sobre coliformes termotolerantes nem sempre significa que as amostras testadas estejam igualmente isentas de outros patógenos intestinais. A importância em se estudar a ocorrência da E. coli se deve ao fato dessa ser a única espécie, dentro da família Enterobacteriaceae, que tem origem exclusivamente fecal.

Cabrini et al. (2001) ressaltam que a presença de coliformes totais não significa necessariamente a ocorrência de contaminação fecal, mas esse dado é importante por indicar erros em condições higiênicas. Assim, a presença de coliformes totais pode ter relação direta com contaminantes nas tubulações e demais instrumentos utilizados para a captação e armazenamento da água do Rio Corda.

A médias dispostas na Tabela 1 mostram que os resultados para UFC's de E. cloacae foram muito maiores que o total de UFC's de E. coli. Resultado parecido também foi encontrado por Moretto (2018) que identificou uma prevalência 65\% para E. cloacae em amostras de coleções hídricas de Salvador e área rural 
da Bahia. Cabe ressaltar também que o Desvio Padrão mostra que houve uma variação maior nos valores do Número Mais Provável (NMP) de Unidades Formadores de Colônias (UFC's)/100 mL de E. cloacae das amostras testadas do que o comparado para E. coli que demonstrou um Desvio Padrão bem menor, por tanto, com uma ocorrência mais harmonioso entorno da média.

Moretto (2018) também ressalta que E. cloacae é mais prevalente em águas superficiais e solo de áreas rurais do que a contagem de $E$. coli, podendo ter relação com a dispersão de fezes de animais, enquanto a $E$. coli é mais prevalente em corpos d'água de áreas urbanas, resultado da densidade populacional maior, levando a maior descarte inapropriado de dejetos. Sobre as correlações estatísticas realizadas, a Figura 2 mostrou que o grupo das Enterobacter cloacae foi o grande responsável pelo resultado alarmante de NMP de colônias para Coliformes totais.

As Enterobacters sp. são bactérias Gram-negativas que fazem parte da classe de bactérias coliformes, não pertencente aos coliformes fecais, componente típico do intestino grosso e que são caracterizadas como micróbios patogênicos oportunistas, provenientes de fezes (animais e humanos), água contaminada, esgoto, solo, dentre outras fontes, representando assim sérios riscos à saúde pública (TORTORA et al., 2012).

Os resultados obtidos para o NMP de colônias de bactérias termotolerantes e de coliformes totais também podem estar associados ao período de coleta das amostras uma vez que, devido a harmonia paisagística do entorno do Assentamento PA Cachimbeiro, este recebe um número considerável de visitantes para ecoturismo, balneabilidade no Rio Corda, pesca amadora, dentre outras possibilidades turísticas do local durante o mês de dezembro, o que acentua as possibilidades de poluição e contaminação. Além disso, anterior à comunidade Duas Cachoeiras (local das coletas desse estudo) e subindo em sentido contrário ao curso do rio, existem várias outras comunidades instaladas às margens do rio e que podem estar contribuindo para a contaminação da água que chega na área da comunidade Duas Cachoeiras.

Em estudo semelhante, Ferreira et al. (2017) destacaram que o fato da água consumida pela comunidade ser proveniente do rio, em uma localidade tipicamente rural e com a presença de animais próximos, dificulta a manutenção da potabilidade da água. Fato esse agravado pela falta de coleta dos resíduos sólidos produzidos pela rotina domiciliar da comunidade, que acaba descartando-os de forma inapropriada ou mesmo lançando-os diretamente no rio.

\section{CONCLUSÕES}

De acordo com o que estabelece a Portaria de Consolidação $N^{\circ} 5$, de 28 de setembro de 2017, do Ministério da Saúde, conclui-se que a água usada para hidratação pela grande maioria dos moradores da comunidade Duas Cachoeiras, do Assentamento PA Cachimbeiro, Vila Real, no município de Barra do Corda/MA, encontra-se fora dos padrões estabelecidos por lei, oferecendo graves riscos à saúde e requerendo ações de intervenção na rotina doméstica dos assentados, como forma de prover qualidade de vida às famílias estabelecidas no local.

Mesmo sendo necessário mais análises para um resultado mais preciso, os dados aqui obtidos demostram uma fragilidade quanto o abastecimento de água na comunidade e os mesmos dados já sinalizam 
para risco grave à saúde uma vez que a água que é usada para hidratação deveria ser isenta de coliformes, independente do período do ano ou da quantidade de vezes que se faça análise microbiológica da mesma.

Com relação ao pH a mesma portaria do Ministério da Saúde, citada acima, prevê que o pH da água seja mantido na faixa de 6,0 a 9,5 e todas as amostras estão enquadradas dentro dessa faixa aceitável para esse parâmetro, indicando que a água não está sofrendo poluição por dejetos químicos que possam alterar o seu potencial hidrogeniônico variando a concentração de íons de Hidrogênio $(\mathrm{H}+)$ para além do estabelecido em lei. Além disso é possível também concluir que, se nas análises foi identificado a presença de colônias de bactérias termotolerantes, bactérias típicas do cólon de animais homeotérmicos, é porque o corpo d'água em questão tem recebido excreção de fezes humanas proveniente de esgotamento doméstico inadequado.

Conclui-se assim que, como o Rio Corda é um recurso explorado por diversas comunidades que o margeiam, há a necessidade de uma ação coletiva de todas essas de modo a garantir a preservação dos ambientes aquáticos que o compõe e não favorecer a poluição e contaminação cumulativa ao longo do curso do rio, bem como requerendo do poder público ações que contemplem o saneamento básico e o tratamento de água para minimizar os riscos à saúde coletiva dos moradores da comunidade Duas Cachoeiras, no Assentamento PA Cachimbeiro, povoado Vila Real, em Barra do Corda/MA.

\section{REFERÊNCIAS}

BRASIL. Portaria de Consolidação n. 5, de 28 de setembro de 2017. Capítulo V - Da Vigilância em Saúde. Anexo XX Controle e vigilância da qualidade da água para consumo humano e seu padrão de potabilidade. Brasília: Ministério da Saúde, 2017.

BARRELL, R.; BENTON, C.; BOYD, P.; CARTWRIGHT, R.; CHADA, C.; COLBOURNE, J.; COLE, S.; COLLEY, A.; DRURY, D.; GODFREE, A.; HUNTER, P.; LEE, J.; MACHRAY, P.; NICHOLS, G.; S ARTORY, D.; SELLWOOD, J.; WATKINS, J.. The Microbiology of Drinking Water - Part 1 - Water Quality and Public Health: methods for the examination of waters and associated materials. Bristol: Environment Agency, 2002.

CABRINI, K. T.; GALLO, C. R.. Microbiological quality of spring mineral water and bottled mineral water. In: CONGRESSO BRASILEIRO DE MICROBIOLOGIA, 11. Anais. Foz do Iguaçú, 2001.

FERREIRA, F. S.; QUEIROZ, T. M.; SILVA, T. V.; ANDRADE, A. C. O.. À margem do rio e da sociedade: a qualidade da água em uma comunidade quilombola no estado de Mato Grosso. Saúde e Sociedade. São Paulo, v.26, n.3, p.822-828, 2017. DOI: https://doi.org/10.1590/s0104-12902017166542

GREGHI, S. Q... Avaliação da eficiência de métodos rápidos usados para a deteç̧ão de Coliformes Totais e Coliformes Fecais em amostras de água em comparação técnicas de fermentação em tubos múltiplos. Dissertação (Mestrado em Alimentos e Nutrição) - Universidade Estadual Paulista, Araraquara, 2005.

MARIANO, M. B.; VIDAL, C. M. S.; SOUSA, J. B. Avaliação da Qualidade Microbiológica da Água para Balneabilidade do Salto Manduri, Prudentópolis - PR. In: SEMANA DA
ENGENHARIA AMBIENTAL, 6. Anais. Campus Irati, Prudentópolis, 2008.

MORETTO, V. T.. Avaliação microbiológica da água e o perfil de resistência antimicrobiana em enterobactérias de coleções hídricas de Salvador e área rural da Bahia. Dissertação (Mestrado em Biotecnologia em Saúde e Medicina Investigativa) - Instituto Gonçalo Moniz, Salvador, 2018.

ODUM, E. P.; BARRETT, G. W.. Fundamentos de Ecologia. 5 ed. São Paulo: Cengage Learning, 2008.

PORTO, M. A. L.; OLIVEIRA, A. M.; FAI, A. E. C.; STAMFORD, T. L. M.. Coliformes em água de abastecimento de lojas fast food da Região Metropolitana de Recife (PE, Brasil). Ciência \& Saúde Coletiva, v.16, n.5, p.2653-2658, 2011. DOI: https://doi.org/10.1590/S1413-81232011000500035

SANTOS, J. A.; SILVA, J. X.; REZENDE, A. J.. Avaliação microbiológica de coliformes totais e termotolerantes em água e bebedouros de uma escola pública no Gama Distrito Federal. REVISA, v.1, p.11-8, 2014.

SILVA, L. M.; SOUZA, E. H.; ARREBOLA, T. M.; JESUS, G. A.. Ocorrência de um surto de hepatite $A$ em três bairros do município de Vitória/ES e sua relação com a qualidade da água de consumo humano. Ciência \& Saúde Coletiva, v.14, n.6, p.2163-2167, 2009. DOI: https://doi.org/10.1590/S1413-81232009000600023

SOUZA, H. R.; CORRÊA, A. M. S.; CRUZ-BARROS, M. A. V.; ALBUQUERQUE, P. M. C.. Espectro polínico da própolis de Scaptotrigona aff. postica (Hymenoptera, Apidae, Meliponini) em Barra do Corda, MA, Brasil. Acta Amazônica, 
v.45, n.3, p.307-316, 2015. DOI:

https://doi.org/10.1590/1809-4392201403663

TORTORA, G. J.; FUNKE, B. R.; CASE, C. L.. Microbiologia. 10 ed. Porto Alegre: Artmed, 2012.

VIEIRA, W. F. S.; SANTOS, D. S. V.; MORAES, P. S. S..

Determinação do índice de coliformes fecais do balneário
Veneza em Caxias (MA). Cadernos Cajuína, v.1, n.2, p.92-99, 2016.

VILLELA, L. C.; CALDAS, V. T.; GAMBA, R. C.. Análise Microbiológica em Águas Minerais envasadas em embalagens de $510 \mathrm{ml}$, comercializadas no Município de Santos/SP. Revista Ceciliana, São Paulo, p.4-6, 2010.

A CBPC - Companhia Brasileira de Produção Científica (CNPJ: 11.221.422/0001-03) detém os direitos materiais desta publicação. Os direitos referem-se à publicação do trabalho em qualquer parte do mundo, incluindo os direitos às renovações, expansões e disseminações da contribuição, bem como outros direitos subsidiários. Todos os trabalhos publicados eletronicamente poderão posteriormente ser publicados em coletâneas impressas sob coordenação da Sustenere Publishing, da Companhia Brasileira de Produção Científica e seus parceiros autorizados. Os (as) autores (as) preservam os direitos autorais, mas não têm permissão para a publicação da contribuição em outro meio, impresso ou digital, em português ou em tradução. 